\title{
Effect of Additives on the Direct Electrodeposition of Copper From Acid Solution Containing 20 g/L Copper(II)
}

\author{
Heng Wang ${ }^{1,2}$, Jianhang Hu ${ }^{1,2}$, Kongzhai Li ${ }^{1,2}$, Yu Wang $^{1,2}$, Feng Zhang ${ }^{1,2}$, Hua Wang ${ }^{1,2, *}$ \\ ${ }^{1}$ Engineering Research Center of Metallurgical Energy Conservation and Emission Reduction of \\ Ministry of Education, Kunming University of Science and Technology, Kunming 650093, China. \\ ${ }^{2}$ Faculty of Metallurgical and Energy Engineering, Kunming University of Science and Technology, \\ Kunming 650093, China. \\ *E-mail: wanghua65@163.com
}

doi: $10.20964 / 2021.01 .40$

Received: 23 September 2020 / Accepted: 3 November 2020 / Published: 30 November 2020

The effect of 3-mercapto-1-propanesulfonate sodium salt (MPS), polyethylene glycol (PEG), thiourea (TU) and ethylenethiourea (ETU) on copper electrodeposition from acidic sulfate electrolyte with low $\mathrm{Cu}^{2+}$ concentration was investigated by linear sweep voltammetry (LSV), and chronoamperometric and electrochemical impedance spectroscopy (EIS) measurements. The LSV experimental results showed that all additives have inhibitory effects on copper electrodeposition. The results of the chronoamperometric experiments suggested that copper electrodeposition was related to threedimensional instantaneous nucleation in the diffusion-controlled regime regardless of the presence of the additives. In agreement with the LSV results, EIS experiments revealed the influence of the additives on the electric double layer during the electrodeposition process. MPS and PEG were found to inhibit the electrodeposition of copper through direct adsorption on the cathode surface, while TU and ETU produce stronger inhibition through complex intermediate reactions. Scanning electron microscopy images showed that the addition of TU and ETU resulted in flatter and finer-grained copper electrodeposits. TU and its derivatives are considered to be suitable additives for direct copper electrodeposition at low copper ion concentration.

Keywords: electrodeposition; low $\mathrm{Cu}^{2+}$ concentration; additives; nucleation; electrodeposit analysis

\section{$\underline{\text { FULL TEXT }}$}

(C) 2021 The Authors. Published by ESG (www.electrochemsci.org). This article is an open access article distributed under the terms and conditions of the Creative Commons Attribution license (http://creativecommons.org/licenses/by/4.0/). 